\title{
Effect of Cutting Type, Indol-3-Butyric Acid and the Growing Season on Rooting of Stem Cuttings of Rosa hybrida Cv Eiffel Tower \\ Azza A. Tawfik ${ }^{1}$; O. H. M. Ibrahim ${ }^{1}$; E. Y. Abdul-Hafeez ${ }^{1}$ and Samar A. Ismail ${ }^{2}$ \\ ${ }^{1}$ Ornamental Plants and Landscape Gardening Department, Faculty of Agriculture, Assiut \\ University, 71526, Egypt \\ ${ }^{2}$ Horticulture Department, Faculty of Agriculture, New valley branch, Assiut University, Egypt
}

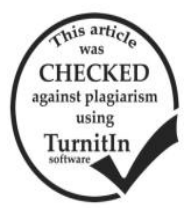

\section{ABSTRACT}

A field experiment was conducted for two successive years to investigate the conventional propagation of Rosa hybrida cv. Eiffel Tower using stem cuttings as affected by the growing season of the year, cutting type and the application of indol-3-butyric acid (IBA) at different concentrations. Uniform cutting types $\sim 15-20 \mathrm{~cm}$ long (apical, median and basal) were collected from the current year growth of healthy mother plants. Then the cutting bases $(2-3 \mathrm{~cm})$ were soaked for 20 minutes in different concentrations of IBA ( 0 , $500,1000$ and $1500 \mathrm{ppm})$ and the lower end of the cuttings were stuck into $14-\mathrm{cm}$ plastic pots filled with a peat: perlite mixture $(1: 1 \mathrm{v} / \mathrm{v})$. The obtained results statistically analyzed by ANOVA showed that rooting percentage of stem cuttings, number of roots and root length varied according to cutting type, concentration of IBA and growing season. The median cutting type was significantly superior to the other types in both autumn and spring seasons. IBA application significantly improved rooting percentage, root number and root length of the treated cuttings comparing to the untreated ones (control). A significant interaction between cutting type and IBA concentrations was observed on most of the characteristics measured during the autumn season only.

Keywords: Apical cuttings, basal cuttings, cutting position, IBA, median cuttings, vegetative propagation

\section{INTRODUCTION}

Roses are well - known as ornamental plants for thousands years and nowadays, it is an economical and commercial cut flowers preferred by many consumers. Roses have an attractive colors, shape and size, in addition to long post- harvest life of its flowers. Although, the majority of roses are native to Asia, while others originate from Europe, North America and Africa, roses can be found throughout the world.

The genus Rosa includes more than 100 species and thousands of cultivars and belongs to Rosaceae family. Species, cultivars and hybrids are all widely grown for their beauty and often are fragrant. Most of the modern rose cultivars are the result of hybridization, selection and mutations in breeding programs. Roses are usually propagated by grafting methods (Kroin and Hortus, 2015) or stem cutting and subsequently growing on their own roots (Manners, 2014).

Rosa hybrida cv Eiffel Tower is one of the most popular and preferable cultivars in the Egyptian market. It tolerates hot, dry Mediterranean climate and flowers throughout the entire growing season. Eiffel Tower produces rich pink flowers on strong stems of 0.5-0.75 m length. Its pink flowers have a delightful fragrance and used in flowers arrangement because of its long vase-life. Moreover, it is relatively disease resistant. This rose was bred and released by David Armstrong and Herbert Swim, in the USA, almost 50 years ago. However, certain species of wild roses are faced with unreliable climate and may be listed as endangered species because of the habitat loss. At our Experimental Farm, Eiffel Tower is usually propagated by grafting method which needs well trained hands and/or stock stem cuttings where no clear information how successful is this method in preserving such important cultivar. Up to our knowledge, no previous reports have been published using stem cuttings for the propagation of the Eiffel Tower cultivar. However, several other rose cultivars have been reported to be successfully propagated by stem cuttings. Rooting success was influenced by cutting type as demonstrated by Al-Saqri and Alderson (1996) on $R$. centifolia, the season as stated by Abbas et al., (2006) on $R$. damascene and IBA concentration according to Akhtar et al., (2015) on R. centifolia.
Thus the aim of this study was to expand cultivation of Rosa hybrida cv Eiffel Tower and produce high quantities of genetically homogenous plants. Furthermore, the investigation aimed to study the conventional propagation by stem cuttings as affected by the growing seasons of the year, cutting type and the application of IBA at different concentrations.

\section{MATERIALS AND METHODS}

The current study was conducted at the Experimental Farm, Faculty of Agriculture, Assiut University during two successive seasons to investigate the conventional propagation of Rosa hybrida cv. Eiffel Tower by stem cuttings.

\section{Plant material}

Stem cuttings were collected from the current year growth of healthy mother plants of Rosa 'Eiffel Tower' grown at the Floriculture Nursery. Uniform cuttings (15-20 $\mathrm{cm}$ long) were prepared using clean sharp scissors, so that the lower cut was made just below a node. The cuttings were defoliated except the apical ones where one leaf was left per cutting.

Treatments

Three different types (apical, median, and basal) cuttings were taken during two seasons (autumn and spring). Then all the cutting bases $(2-3 \mathrm{~cm})$ were soaked for 20 minutes in different concentrations of IBA $(0,500$, 1000 and $1500 \mathrm{ppm}$ ). IBA used was water soluble IBA-K. The cuttings dipped in distilled water served as a control treatment. Cuttings were immediately planted into $14-\mathrm{cm}$ plastic pots containing a peat: perlite mixture $(1: 1 \mathrm{v} / \mathrm{v})$ and kept under greenhouse conditions and further covered with a plastic sheet to keep high humidity and warm temperature conditions. This experiment was repeated in the same manner under typical conditions for two successive years (2015/2016 and 2016/2017).

\section{Experimental design}

The treatments were arranged in a complete randomized block design (split-plot). The main plots comprehended the three cutting types which were further subdivided into sub-plots representing IBA concentrations. Each plot comprised five pots with 5 cuttings each. Three replicates were included to have in total 75 cuttings for 
each treatment. Each of spring and autumn seasons was statistically analyzed as a different experiment.

Data recorded

After 2 months, data were recorded on the following parameters:

- Rooting percentage: calculated as the number of rooted cuttings divided by the total planted cuttings multiplied by 100.

- Root length (cm): mean root length/cutting

- Number of roots

- Shoot length (cm): length of lateral shoots induced on the cutting

- Number of leaves: number of newly developed leaves on the formed lateral shoots

\section{Statistical analysis}

Data were subjected to statistical analysis using ANOVA test according to Snedecor and Cochran (1973) and the means were compared using LSD test according to Gomez and Gomez (1984).

\section{RESULTS}

\section{Rooting of Rosa 'Eiffel Tower' stem cuttings}

\section{Rooting Percentage}

Rooting percentage of rose stem cuttings varied according to cutting type, concentration of IBA and growing season. Position of cutting on the branch significantly affected rooting $\%$, where the median cutting type was significantly superior to other types, in most cases (Table 1). This trend was noticed in both autumn and spring seasons of both years of the experiment except in autumn of the first year where rooting \% of the basal cuttings $(19.59 \%)$ was higher than the rooting $\%$ of the median ones $(17.50 \%)$ with no significant differences between them. Rooting \% of median cuttings and the basal ones were significantly better than the apical cuttings. Moreover, apical cuttings taken during autumn didn't almost show any response (Table 1).

Auxin application significantly improved rooting percentage of the treated cuttings comparing to the untreated ones (control). Generally, efficiency of IBA increased as the concentration used was increased. The highest concentration $(1500 \mathrm{ppm})$ recorded the best results followed by $1000 \mathrm{ppm}$ with a significant difference between them.

The interaction effect between cutting type and IBA concentrations was significant during the autumn season only in both years. However, median or basal cuttings treated with IBA at $1500 \mathrm{ppm}$ showed the highest rooting $\%$ (Table 1).

Table 1. Rooting \% of Rosa hybrida 'Eiffel Tower' stem cuttings as affected by cutting type (apical, median and basal) and IBA at 0, 500, 1000 and $1500 \mathrm{ppm}$ in both autumn and spring seasons during 2015/2016 and 2016/2017.

\begin{tabular}{|c|c|c|c|c|c|c|c|c|}
\hline \multirow{4}{*}{ IBA (ppm) } & \multicolumn{8}{|c|}{ First Year } \\
\hline & \multicolumn{8}{|c|}{ Cutting type } \\
\hline & \multicolumn{4}{|c|}{ Autumn } & \multicolumn{4}{|c|}{ Spring } \\
\hline & apical & median & basal & Mean & apical & median & basal & Mean \\
\hline 0 & 0.00 & 0.00 & 15.33 & 5.11 & 20.00 & 33.33 & 26.67 & 26.67 \\
\hline 500 & 0.00 & 20.00 & 18.67 & 12.89 & 33.33 & 40.00 & 40.00 & 37.78 \\
\hline 1000 & 6.33 & 20.00 & 21.01 & 15.78 & 40.00 & 53.33 & 40.00 & 44.44 \\
\hline 1500 & 0.00 & 30.00 & 23.33 & 17.78 & 46.67 & 73.33 & 46.67 & 55.56 \\
\hline Mean & 1.58 & 17.50 & 19.59 & & 35.00 & 50.00 & 38.33 & \\
\hline \multicolumn{9}{|l|}{ LSD 5\% } \\
\hline Cutting type & & 7.67 & & & & 5.97 & & \\
\hline IBA & & 2.33 & & & & 9.34 & & \\
\hline Interaction & & 4.04 & & & & $\mathrm{NS}^{*}$ & & \\
\hline \multirow{4}{*}{ IBA (ppm) } & \multicolumn{8}{|c|}{ Second Year } \\
\hline & \multicolumn{8}{|c|}{ Cutting type } \\
\hline & \multicolumn{4}{|c|}{ Autumn } & \multicolumn{4}{|c|}{ Spring } \\
\hline & apical & median & basal & Mean & apical & median & basal & Mean \\
\hline 0 & 0.00 & 0.00 & 0.00 & 0.00 & 10.00 & 16.67 & 0.00 & 8.89 \\
\hline 500 & 0.00 & 20.00 & 0.00 & 6.67 & 13.33 & 33.33 & 10.00 & 18.89 \\
\hline 1000 & 0.00 & 20.00 & 13.33 & 11.11 & 20.00 & 53.33 & 26.67 & 33.33 \\
\hline 1500 & 0.00 & 20.00 & 40.00 & 20.00 & 33.33 & 66.67 & 66.67 & 55.56 \\
\hline Mean & 0.00 & 15.00 & 13.33 & & 19.17 & 42.5 & 25.83 & \\
\hline \multicolumn{9}{|l|}{ LSD 5\% } \\
\hline Cutting type & & 3.78 & & & & NS & & \\
\hline IBA & & 3.30 & & & & 13.61 & & \\
\hline Interaction & & 5.82 & & & & NS & & \\
\hline
\end{tabular}

*NS= not significant

\section{Number of roots}

Data in Table 2 showed a significant effect of cutting types on root number in the autumn seasons only. The median and basal cuttings formed higher number of roots compared to the apical ones in autumn seasons of both years. In spring season, apical cuttings produced more roots in the second year with no significant different among the three types of cuttings.

Treating cuttings with IBA significantly enhanced number of roots comparing with the untreated cuttings (Table 2). Significant increase in number of roots was noticed as the concentration of IBA was increased. The highest concentration of IBA (1500 ppm) led to the highest 
number of roots during both autumn and spring in both years.

The interaction effect between cutting type and IBA concentrations were proved significant only in the autumn season of both years (Table 2). Median or basal cutting types treated with IBA at $1500 \mathrm{ppm}$ showed the highest root number $(7.20,7.17$ and $6.67,6.17$ roots per cutting) in the autumn seasons of first and second year respectively. It was generally noticed that number of roots was higher when the cuttings were taken in the autumn season than those taken in spring.

Table 2. Number of roots of Rosa hybrida 'Eiffel Tower' stem cuttings as affected by cutting type (apical, median and basal) and IBA at 0, 500, 1000 and $1500 \mathrm{ppm}$ in both autumn and spring seasons during 2015/2016 and 2016/2017

\begin{tabular}{|c|c|c|c|c|c|c|c|c|}
\hline \multirow{4}{*}{ IBA (ppm) } & \multicolumn{8}{|c|}{ First Year } \\
\hline & \multicolumn{8}{|c|}{ Cutting type } \\
\hline & \multicolumn{4}{|c|}{ Autumn } & \multicolumn{4}{|c|}{ Spring } \\
\hline & apical & median & basal & Mean & apical & median & basal & Mean \\
\hline 0 & 0.00 & 0.00 & 2.67 & 0.89 & 0.57 & 0.53 & 1.90 & 1.00 \\
\hline 500 & 0.00 & 4.83 & 5.17 & 3.33 & 2.67 & 1.50 & 3.33 & 2.50 \\
\hline 1000 & 0.33 & 6.43 & 6.03 & 4.30 & 3.33 & 2.17 & 3.67 & 3.06 \\
\hline 1500 & 0.00 & 7.20 & 7.17 & 4.79 & 4.17 & 4.53 & 4.17 & 4.29 \\
\hline Mean & 0.10 & 4.62 & 5.26 & & 2.68 & 2.18 & 3.27 & \\
\hline \multicolumn{9}{|l|}{ LSD 5\% } \\
\hline Cutting type & \multicolumn{3}{|c|}{1.50} & \multicolumn{5}{|c|}{ NS } \\
\hline IBA & \multicolumn{3}{|c|}{0.92} & \multicolumn{5}{|c|}{0.99} \\
\hline Interaction & \multicolumn{3}{|c|}{1.59} & \multicolumn{5}{|c|}{ NS } \\
\hline \multirow{4}{*}{ IBA (ppm) } & \multicolumn{8}{|c|}{ Second Year } \\
\hline & \multicolumn{8}{|c|}{ Cutting type } \\
\hline & \multicolumn{4}{|c|}{ Autumn } & \multicolumn{4}{|c|}{ Spring } \\
\hline & apical & median & basal & Mean & apical & median & basal & Mean \\
\hline 0 & 0.00 & 0.00 & 0.00 & 0.00 & 2.17 & 1.00 & 0.00 & 1.06 \\
\hline 500 & 0.00 & 1.33 & 0.00 & 0.44 & 3.00 & 1.40 & 2.00 & 2.13 \\
\hline 1000 & 0.00 & 4.00 & 2.67 & 2.22 & 5.17 & 2.60 & 2.93 & 3.57 \\
\hline 1500 & 0.00 & 6.67 & 6.17 & 4.28 & 6.67 & 3.60 & 3.87 & 4.71 \\
\hline Mean & 0.00 & 3.00 & 2.21 & & 4.25 & 2.15 & 2.20 & \\
\hline \multicolumn{9}{|l|}{ LSD 5\% } \\
\hline Cutting type & & 1.98 & & & & NS & & \\
\hline IBA & & 1.37 & & & & 0.92 & & \\
\hline Interaction & & 2.38 & & & & NS & & \\
\hline
\end{tabular}

*NS= not significant

3. Root length (cm)

The obtained data presented in Table 3 showed that the cutting types had no significant effect on root length in spring seasons of both years. However, basal and median cuttings had the longest roots in both autumn and spring seasons of the first years compared to the apical cuttings. In autumn season of both years, apical cutting had almost no rooting response and consequently almost no root length was recorded.

IBA-treated cuttings registered significant increase in root length comparing with the untreated ones (Table 3). Increasing the concentration of IBA up to $1500 \mathrm{ppm}$ led to a gradually significant enhancement in root length. Cuttings taken in either autumn or spring in both years and treated with the highest concentration of IBA (1500 ppm) had the longest roots, except for those taken in autumn of the first year, where IBA at $1000 \mathrm{ppm}$ resulted in the longest roots $(2.56 \mathrm{~cm})$ followed by IBA at $1500 \mathrm{ppm}$ $(1.20 \mathrm{~cm})$.

The obtained results statistically analyzed by ANOVA showed a significant interaction effect between cutting type and IBA concentrations during the autumn season only in both years (Table 3 ). Basal cuttings treated with IBA at $1500 \mathrm{ppm}$ showed the highest root length ( 3.67 and $4.5 \mathrm{~cm})$ in autumn of both years respectively.

\section{Shoot length $(\mathrm{cm})$}

The effect of cutting types on the growth of newly induced shoots on rooted cuttings is presented in Table 4 .
Although cutting type had no statistically significant effect on shoot length in all cases, basal cuttings produced noticeably longer shoots than the other types in both seasons and years.

Application of IBA at any of the concentrations involved in the current study improved growth of induced shoots in comparison to the untreated cuttings (Table 4). Both concentrations of 1000 and $1500 \mathrm{ppm}$ produced the longest shoots. Application of IBA at the highest concentration (1500 ppm) significantly produced longest shoots than the other concentrations (500 and $1000 \mathrm{ppm}$ ) in all cases except in autumn of the first year.

The interaction between cutting type and IBA concentrations had a significant effect on shoot length during both seasons of autumn and spring in the two years of the study (Table 4). Application of IBA at the highest concentration (1500 ppm) to basal cuttings induced the longest shoots in both seasons and years.

\section{Number of leaves}

Data presented in Table 5 indicated that, similar to the previously presented data of shoot length, cutting type had no significant effect on number of leaves. It is clear that both median and basal cuttings produced more leaves than the apical cuttings in both seasons and years.

Treating the cuttings with IBA up to $1000 \mathrm{ppm}$ significantly increased the number of leaves comparing to the untreated cuttings (Table 5). The higher concentration of IBA $(1500 \mathrm{ppm})$ reduced the number of leaves comparing 
with the cuttings treated with 1000 ppm but with no significant difference.

The interaction effect between cutting type and IBA concentrations was significant during the autumn season of the two years of the study (Table 5). It was noticeable that median and basal cuttings produced high number of leaves when treated with IBA at $1000 \mathrm{ppm}$ in most cases. In the autumn season of the first year, median cuttings treated with IBA at 500 produced the highest number of leaves (8.73 leaves/ cutting) with no significant difference between the basal cuttings treated with 1000 ppm (7.53 leaves/cutting).

Table 3. Root length (cm) of Rosa hybrida 'Eiffel Tower' stem cuttings as affected by cutting type (apical, median and basal) and IBA at 0, 500, 1000 and 1500 ppm in both autumn and spring seasons during 2015/2016 and 2016/2017.

\begin{tabular}{|c|c|c|c|c|c|c|c|c|}
\hline \multirow{4}{*}{ IBA (ppm) } & \multicolumn{8}{|c|}{ First Year } \\
\hline & \multicolumn{8}{|c|}{ Cutting type } \\
\hline & \multicolumn{4}{|c|}{ Autumn } & \multicolumn{4}{|c|}{ Spring } \\
\hline & apical & median & basal & Mean & apical & median & basal & Mean \\
\hline 0 & 0.00 & 0.00 & 1.50 & 0.50 & 0.60 & 0.57 & 1.57 & 0.91 \\
\hline 500 & 0.00 & 1.17 & 2.43 & 1.20 & 2.23 & 2.00 & 2.67 & 2.30 \\
\hline 1000 & 2.67 & 1.83 & 3.17 & 2.56 & 2.33 & 2.53 & 3.67 & 2.84 \\
\hline 1500 & 0.00 & 1.70 & 3.67 & 1.20 & 3.00 & 3.27 & 4.33 & 3.53 \\
\hline Mean & 0.67 & 1.18 & 2.69 & & 2.04 & 2.09 & 3.06 & \\
\hline \multicolumn{9}{|l|}{$\overline{L S D} 5 \%$} \\
\hline Cutting type & & 0.79 & & & & NS & & \\
\hline IBA & & 0.32 & & & & 1.09 & & \\
\hline Interaction & & 0.55 & & & & NS & & \\
\hline \multirow{4}{*}{ IBA (ppm) } & \multicolumn{8}{|c|}{ Second Year } \\
\hline & \multicolumn{8}{|c|}{ Cutting type } \\
\hline & \multicolumn{4}{|c|}{ Autumn } & \multicolumn{4}{|c|}{ Spring } \\
\hline & apical & median & basal & Mean & apical & median & basal & Mean \\
\hline 0 & 0.00 & 0.00 & 0.00 & 0.00 & 1.00 & 2.03 & 0.00 & 1.01 \\
\hline 500 & 0.00 & 1.67 & 0.00 & 0.56 & 2.22 & 2.47 & 1.17 & 1.95 \\
\hline 1000 & 0.00 & 2.33 & 1.67 & 1.33 & 3.00 & 3.11 & 2.40 & 2.84 \\
\hline 1500 & 0.00 & 5.00 & 4.50 & 3.17 & 3.67 & 3.90 & 3.10 & 3.56 \\
\hline Mean & 0.00 & 2.25 & 1.54 & & 2.47 & 2.88 & 1.67 & \\
\hline \multicolumn{9}{|l|}{ LSD 5\% } \\
\hline Cutting type & & 0.96 & & & & NS & & \\
\hline IBA & & 0.60 & & & & 0.48 & & \\
\hline Interaction & & 1.05 & & & & NS & & \\
\hline
\end{tabular}

Table 4. Shoot length (cm) of Rosa hybrida 'Eiffel Tower' stem cuttings as affected by cutting type (apical, median and basal) and IBA at 0, 500, 1000 and $1500 \mathrm{ppm}$ in both autumn and spring seasons during 2015/2016 and 2016/2017.

\begin{tabular}{|c|c|c|c|c|c|c|c|c|}
\hline \multirow{4}{*}{ IBA (ppm) } & \multicolumn{8}{|c|}{ First Year } \\
\hline & \multicolumn{8}{|c|}{ Cutting type } \\
\hline & \multicolumn{4}{|c|}{ Autumn } & \multicolumn{4}{|c|}{ Spring } \\
\hline & apical & median & basal & Mean & apical & median & basal & Mean \\
\hline 0 & 0.00 & 0.00 & 14.33 & 4.78 & 3.33 & 1.67 & 2.00 & 2.33 \\
\hline 500 & 0.00 & 11.00 & 12.00 & 7.67 & 2.40 & 3.00 & 2.83 & 2.74 \\
\hline 1000 & 2.67 & 12.00 & 15.11 & 9.93 & 4.43 & 5.03 & 7.83 & 5.77 \\
\hline 1500 & 0.00 & 14.33 & 17.00 & 10.44 & 9.47 & 7.50 & 26.87 & 14.61 \\
\hline Mean & 0.69 & 9.33 & 14.61 & & 4.91 & 4.30 & 9.88 & \\
\hline \multicolumn{9}{|l|}{ LSD $5 \%$} \\
\hline Cutting type & \multicolumn{3}{|c|}{ NS } & \multicolumn{5}{|c|}{ NS } \\
\hline IBA & \multicolumn{3}{|c|}{4.09} & \multicolumn{5}{|c|}{3.72} \\
\hline Interaction & \multicolumn{3}{|c|}{7.09} & \multicolumn{5}{|c|}{6.44} \\
\hline \multirow{4}{*}{ IBA (ppm) } & \multicolumn{8}{|c|}{ Second Year } \\
\hline & \multicolumn{8}{|c|}{ Cutting type } \\
\hline & \multicolumn{4}{|c|}{ Autumn } & \multicolumn{4}{|c|}{ Spring } \\
\hline & apical & median & basal & Mean & apical & median & basal & Mean \\
\hline 0 & 0.00 & 0.00 & 0.00 & 0.00 & 5.00 & 4.67 & 0.00 & 3.22 \\
\hline 500 & 0.00 & 2.67 & 0.00 & 0.89 & 6.17 & 5.67 & 5.33 & 5.72 \\
\hline 1000 & 0.00 & 3.07 & 1.83 & 1.63 & 7.00 & 7.33 & 9.00 & 7.78 \\
\hline 1500 & 0.00 & 5.00 & 9.50 & 4.83 & 9.67 & 8.33 & 12.67 & 10.22 \\
\hline Mean & 0.00 & 2.69 & 2.83 & & 6.96 & 6.50 & 6.75 & \\
\hline \multicolumn{9}{|l|}{ LSD 5\% } \\
\hline Cutting type & & NS & & & & NS & & \\
\hline IBA & & 2.14 & & & & 2.16 & & \\
\hline Interaction & & 3.69 & & & & 3.75 & & \\
\hline
\end{tabular}


Table 5. Number of leaves of Rosa hybrida 'Eiffel Tower' stem cuttings as affected by cutting type (apical, median and basal) and IBA at 0, 500, 1000 and $1500 \mathrm{ppm}$ in both autumn and spring seasons during 2015/2016 and 2016/2017.

\begin{tabular}{|c|c|c|c|c|c|c|c|c|}
\hline \multirow{4}{*}{ IBA (ppm) } & \multicolumn{8}{|c|}{ First Year } \\
\hline & \multicolumn{8}{|c|}{ Cutting type } \\
\hline & \multicolumn{4}{|c|}{ Autumn } & \multicolumn{4}{|c|}{ Spring } \\
\hline & apical & median & basal & Mean & apical & median & basal & Mean \\
\hline 0 & 0.00 & 0.00 & 4.67 & 1.56 & 2.10 & 2.17 & 4.27 & 2.84 \\
\hline 500 & 0.00 & 8.73 & 6.87 & 5.20 & 3.87 & 5.43 & 4.42 & 4.57 \\
\hline 1000 & 2.87 & 7.53 & 7.53 & 5.98 & 7.10 & 6.43 & 9.07 & 7.53 \\
\hline 1500 & 0.00 & 5.27 & 7.00 & 4.09 & 2.23 & 7.67 & 4.42 & 4.77 \\
\hline Mean & 0.72 & 5.38 & 6.52 & & 3.83 & 5.43 & 5.55 & \\
\hline \multicolumn{9}{|l|}{ LSD 5\% } \\
\hline Cutting type & \multicolumn{3}{|c|}{ NS } & \multicolumn{5}{|c|}{ NS } \\
\hline IBA & \multicolumn{3}{|c|}{1.77} & \multicolumn{5}{|c|}{4.31} \\
\hline Interaction & \multicolumn{3}{|c|}{3.06} & \multicolumn{5}{|c|}{ NS } \\
\hline \multirow{4}{*}{ IBA (ppm) } & \multicolumn{8}{|c|}{ Second Year } \\
\hline & \multicolumn{8}{|c|}{ Cutting type } \\
\hline & \multicolumn{4}{|c|}{ Autumn } & \multicolumn{4}{|c|}{ Spring } \\
\hline & apical & median & basal & Mean & apical & median & basal & Mean \\
\hline 0 & 0.00 & 0.00 & 0.00 & 0.00 & 2.27 & 6.33 & 0.00 & 2.87 \\
\hline 500 & 0.00 & 3.67 & 0.00 & 1.22 & 2.60 & 9.67 & 6.00 & 6.09 \\
\hline 1000 & 0.00 & 4.33 & 2.67 & 2.33 & 4.13 & 2.87 & 8.00 & 5.00 \\
\hline 1500 & 0.00 & 1.87 & 2.87 & 1.58 & 4.73 & 3.47 & 2.67 & 3.62 \\
\hline Mean & 0.00 & 2.47 & 1.39 & & 3.43 & 5.59 & 4.17 & \\
\hline \multicolumn{9}{|l|}{ LSD 5\% } \\
\hline Cutting type & & NS & & & & NS & & \\
\hline IBA & & 1.64 & & & & 2.03 & & \\
\hline Interaction & & 4.30 & & & & NS & & \\
\hline
\end{tabular}

*NS= not significant

\section{DISCUSSION}

Propagation by cuttings, known as clonal propagation, has become very important for producing not only rootstock plants but also own-rooted cut-flower roses. It is worth to mention that root initiation may be influenced by a number of endogenous and exogenous factors (Hartmann et al., 2011). Endogenous auxins, carbohydrate status of the cuttings, mineral nutrients content especially nitrogen and other biochemical compounds have a great impact on formation of adventitious roots (Otiende et al., 2017). These endogenous factors are transferred from the stock plants to the propagules when the cuttings are severed and may act as rooting cofactors or auxin transport modulators. Other factors involved in root initiation on stem cuttings include plant species, cutting type, presence of leaves, nutrition of stock plant, wounding, plant growth regulators in addition to time of year, temperature, rooting media, water, humidity and light.

The current study was devoted to investigate the conventional propagaton of Rosa hybrida cv Eiffel Tower by stem cuttings as affected by cutting types (apical, median and basal), the growing season of the year (autumn and spring), and the application of indol-3-butyric acid (IBA) at different concentrations $(0,500,1000$ and 1500 ppm).

\section{Effect of cutting type}

Adventitious root formation and axillary buds breaking may be influenced by the cutting position on stock plant shoot. The data obtained out of the current study revealed that the position of cutting on the branch significantly affected the root formation (Table 1). The median and basal cutting types were significantly superior to the other type in terms of rooting $\%$, and had more root number and length. Cutting origin is an important factor for rooting performance of Rosa hybrida. as has been suggested by several previous studies such as Al-Saqri and Alderson (1996) who stated that medial and basal cuttings of $R$. centifolia gave a better rooting response than apical and sub-apical cuttings. This is may be attributed to the higher content of storage carbohydrates (Hambrick et al., 1991). The difference in rooting ability of the cutting position can be related to the difference in the chemical composition of the shoots (Otiende et al., 2017).

\section{Effect of season}

Autumn has been proved by several authors as the ideal time for taking rose cuttings [Abbas et al. (2006), Ercisli and Guleryuz (1999) and Gunes and Sen (2001)]. However, spring season was the best for planting $R$. centifolia according to the results revealed by Abbas et al. (2006). Besides, Kashefi et al. (2014) compared the performance of rose cuttings taken during March, June and October. They declared that cuttings prepared in March were superior to those prepared in either June or October. Our results indicated that the effect of the season depends on type of cuttings taken and the concentration of the auxin used.

\section{Effect of IBA}

Auxins are one of the major factors known to influence adventitious root development. The effect of auxin application varies according to auxin type and concentration. The results obtained out of the current investigation -the effect of IBA on stem cutting of Rosa hybrida cv Eiffel Tower- revealed that treating cuttings with IBA at any of the concentrations significantly enhanced rooting \%, number of roots and root length comparing with the untreated cuttings in both seasons of 
the two years. Several investigators proved the superiority of IBA as a pretreatment for rose cuttings [(Akhtar et al., (2002), Akhtar et al., (2015), Borowski et al., (1986), Dawa et al., (2017), Susaj et al., (2012)]. In this study, efficiency of IBA increased as the concentration used was increased. The highest concentration $(1500 \mathrm{ppm})$ recorded the best results followed by $1000 \mathrm{ppm}$ in most cases. Similar results were recorded by Krishnamoorthy et al. (2017). They compared between IBA and IAA at different concentrations $(0,500,1000,1500$ and $2000 \mathrm{ppm})$. The best bud sprouting, days to sprout, number of leaves / plant, were recorded at $1500 \mathrm{ppm}$ of IBA. On the other hand, $1000 \mathrm{ppm}$ IBA proved to be superior for root initiation and development of many genotypes of Rosa hybrida than any of the higher concentrations [Dawa et al., (2017), Dawa et al., (2018), Nasri et al., (2015), Yeshiwas et al., (2015)].

\section{REFERENCES}

Abbas, H.; M.J. Jaskani; Z. Hussain and M. Asif (2006): Response of rose cuttings against root promoting hormones during spring and autumn. Int. J. Biol. Biotech., 3 (1): 201-204.

Akhtar, G.; A. Akram; Y. Sajjad; R.M. Balal; M.A. Shahid; H. Sardar; K. Naseem and S.M. Shah (2015): Potential of plant growth regulators on modulating rooting of Rosa Centifolia. . Ame. J. Plant Sci., 6: 659-665.

Akhtar, M.S.; M.A. Khan; A. Riaz and A. Younis (2002): Response of different rose species to different root promoting hormones. Pak. J. Agri. Sci, 39 (4): $297-$ 299.

Al-Saqri, F. and P. G. Alderson (1996): Effects of IBA, cutting type and rooting media on rooting of Rosa centifolia. J. Hortic. Sci., 71 (5): 729-737.

Borowski, E.; L. Kozlowska and M. Wilkowicz (1986): The effect of indole-butyric acid and kinetin on rooting of rose cuttings in winter and summer. Acta Agrobotanica, 39 (1): 59-67.

Dawa, S.; Z.A. Rather; T. Stobgais; T. Angdus; S. Lakdan and P. Tundup (2018): Effect of growth regulators and growth media on the rhizogenesis of some genotypes of rose through stem cuttings. Int. J. Curr. Microbiol. App. Sci., 7 (1): 1138-1147.

Dawa, S; Z.A. Rather; P. Tundup and T. Tamchos (2017): Effect of growth regulators and growth media on rooting of semi hardwood cuttings of rose root stocks. Int. J. Curr. Microbiol. App. Sci. 6 (4): 10421051.

Ercisli, S. and M. Guleryuz (1999): A study of the propagation of the hardwood cuttings of some rose hips. Tr. J. of Agriculture and Forestry, 23(2): 305310.
Gomez, K.A. and A.A. Gomez (1984): Statistical Procedures for Agric. Res., $2^{\text {nd }}$ Ed., John Wily, NY. $680 \mathrm{pp}$.

Gunes, M. and S.M. Sen (2001): A study on propagation ability of some rose hips (Rosa hybrida.) by hardwood cuttings. Bahce 30 (1-2): 17-24.

Hambrick III, C.E; F.T.J. Davies; and H.B. Pemberton (1991): Seasonal changes in carbohydrate nitrogen levels during field rooting of Rosa-multiflora brooks 56 hardwood cuttings. Sci. Hortic. (Amsterdam) 46, 137-146.

Hartmann, H.T.; D.E. Kester; F.T. Davies; and R.L. Geneve (2011): Hartmann and Kester's Plant Propagation: Principles and Practices, 8th ed. Prentice Hall, New Jersey (928 Pp.)

Kashefi, M.; H. Zerei and F. Bahadori (2014): The regulation effect of the growth of indole butyric acid and the time of stem cutting preparation on proliferation of damask rose ornamental shrub. Journal of Ornamental Plants, 4 (4): 49-55.

Krishnamoorthy, C.; B. Subha Shree and B. Suvetha (2017): Effect of NAA and IBA on stem cuttings of rose. Agriculture Update, 12 (1): 88-91.

Kroin, J. and U. Hortus. (2015). PROPAGATION OF ROSES: Stenting-Simultaneously Cutting and Grafting. Hortus USA Articles. https: // www. Researchgate .net / publication/317007874 PROPAGATION_OF_ROSES_Stenting Simultaneously Cutting and Grafting (accessed on May 2018)

Manners M. M. (2014): Propagation roses from cuttings, Florida Southern College http://www. rkdn.org /roses/propagate.asp (accessed on May 2018)

Nasri, F.; A. Fadakar; M.K. Saba and B. Yousefi (2015): Study of indole butyric acid (IBA) effects on cutting rooting improving some of wild genotypes of damask roses (Rosa damascena Mill). Journal of Agricultural Sciences, 60 (3): 263-275.

Otiende, M.A.; J.O. Nyabundi; K. Ngamau and P. Opala (2017): Effects of cutting position of rose rootstock cultivars on rooting and its relationship with mineral nutrient content and endogenous carbohydrates. Scientia Horticulturae 225: 204-212

Snedecor, G.W. and W.G. Cochran (1973): Statistical Methods. Sixth Edition, Iowa State Univ., Press, Ames., Iowa, USA

Susaj, E.; L. Susaj and I. Kallco (2012): Effect of different NAA and IBA concentrations on rooting of vegetative cuttings of two rose cultivars. Research Journal of Agricultural Science, 44 (3): 121-127.

Yeshiwas, T.; M. Alemayehu and G. Alemayehu (2015): Effect indole butyric acid (IBA) and stem cuttings on growth of stenting- propagated rose in Bahir Dar, Ethiopia. World Journal of Agricultural Sciences, 11 (4): 191-197

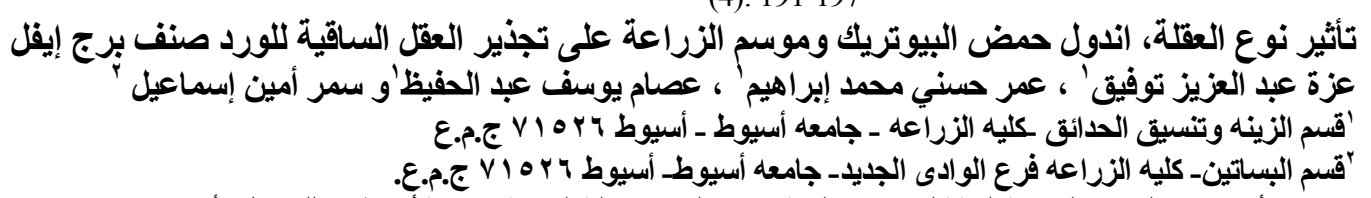

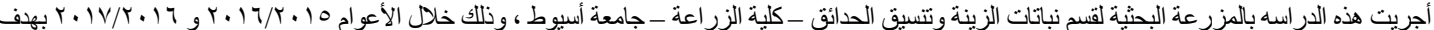

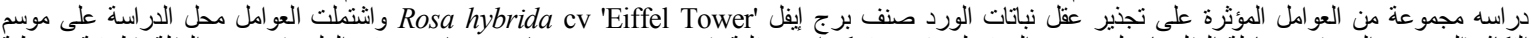

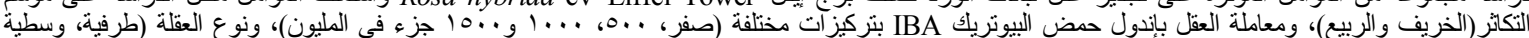

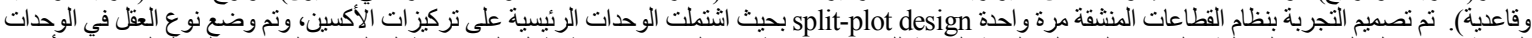

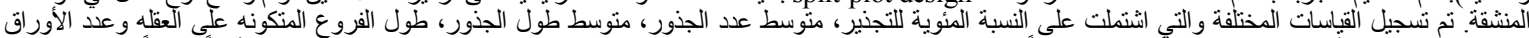

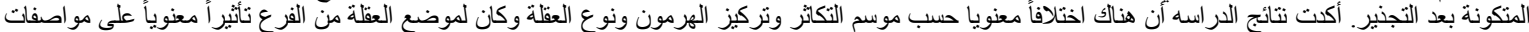

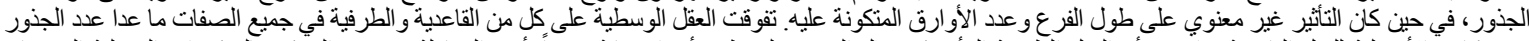

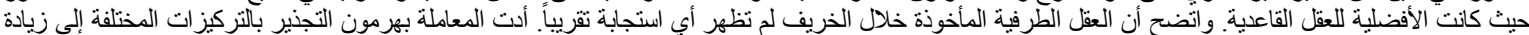

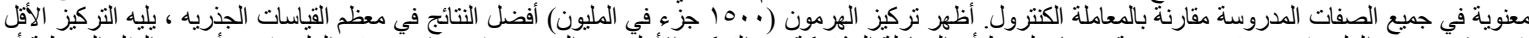

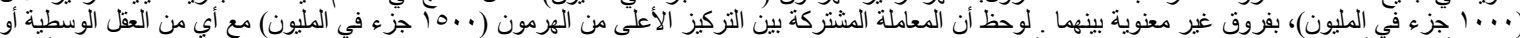

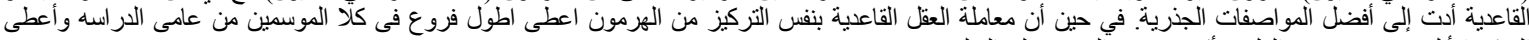

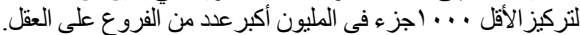

